\title{
Simulating transoceanic migrations of young loggerhead sea turtles: merging magnetic navigation behavior with an ocean circulation model
}

\author{
Nathan F. Putman ${ }^{1, \star}$, Philippe Verley ${ }^{2,3}$, Thomas J. Shay ${ }^{4}$ and Kenneth J. Lohmann ${ }^{1}$ \\ ${ }^{1}$ Department of Biology, University of North Carolina, Chapel Hill, NC 27599, USA, ${ }^{2}$ Laboratoire de Physique des Océans, UMR \\ 6523 CNRS-Ifremer-IRD-UBO, UFR Sciences et Techniques CS 93837, 6 avenue Le Gorgeu, 29238 Brest Cedex 3, France, \\ ${ }^{3}$ Institut de Recherche pour le Développement (IRD), UMR 212 EME, Centre de Recherche Halieutique Méditerranéenne et \\ Tropicale, av. Jean Monnet, B.P. 171, 34203 Sète cedex, France and ${ }^{4}$ Institute for the Environment and Department of Marine \\ Sciences, University of North Carolina, Chapel Hill, NC 27599, USA \\ ${ }^{*}$ Author for correspondence at present address: Initiative for Biological Complexity, North Carolina State University, Raleigh, NC 27695, USA \\ (nathan.putman@gmail.com)
}

Accepted 6 February 2012

\begin{abstract}
SUMMARY
Young loggerhead sea turtles (Caretta caretta) from eastern Florida, USA, undertake a transoceanic migration in which they gradually circle the Sargasso Sea before returning to the North American coast. Loggerheads possess a 'magnetic map' in which regional magnetic fields elicit changes in swimming direction along the migratory pathway. In some geographic areas, however, ocean currents move more rapidly than young turtles can swim. Thus, the degree to which turtles can control their migratory movements has remained unclear. In this study, the movements of young turtles were simulated within a high-resolution ocean circulation model using several different behavioral scenarios, including one in which turtles drifted passively and others in which turtles swam briefly in accordance with experimentally derived data on magnetic navigation. Results revealed that small amounts of oriented swimming in response to regional magnetic fields profoundly affected migratory routes and endpoints. Turtles that engaged in directed swimming for as little as $1-3 \mathrm{~h}$ per day were $43-187 \%$ more likely than passive drifters to reach the Azores, a productive foraging area frequented by Florida loggerheads. They were also more likely to remain within warm-water currents favorable for growth and survival, avoid areas on the perimeter of the migratory route where predation risk and thermal conditions pose threats, and successfully return to the open-sea migratory route if carried into coastal areas. These findings imply that even weakly swimming marine animals may be able to exert strong effects on their migratory trajectories and open-sea distributions through simple navigation responses and minimal swimming.
\end{abstract}

Supplementary material available online at http://jeb.biologists.org/cgi/content/full/215/11/1863/DC1

Key words: distribution, loggerhead sea turtle, dispersal, magnetic map, magnetorecpetion, ocean circulation model.

\section{INTRODUCTION}

In many animals, oriented locomotion in response to specific environmental cues plays a crucial role in guiding movement across various spatial scales (Dingle, 1996). Among species that migrate long distances, directed movement has the potential to shape the geographic distribution of a species, as well as influence fundamental biological processes such as dispersal, gene flow and colonization (Alerstam, 2006; Akesson and Hedenstrom, 2007). For most animals, however, the navigational mechanisms that guide migrations are poorly understood. As a result, few attempts have been made to incorporate realistic navigational processes into models of animal movement or to determine how such behavior might influence animal distributions (Holyoak et al., 2008; Boyer and Walsh, 2010).

The navigation system that guides the migration of young loggerhead turtles (Caretta caretta) is among the most thoroughly studied of any marine animal (Wiltschko and Wiltschko, 2005; Lohmann et al., 2007; Gould, 2011). Young loggerheads from Florida, USA, embark on a transoceanic migration around the Sargasso Sea, a pathway that approximately coincides with the warm-water current system known as the North Atlantic Subtropical Gyre (Carr, 1986; Carr, 1987; Bolten et al., 1998).
Young turtles use positional information in Earth's magnetic field as a kind of 'map' to guide their swimming within the gyre (Lohmann et al., 2007; Lohmann et al., 2012). Specifically, laboratory studies have shown that regional magnetic fields function as navigational markers and elicit changes in swimming direction at different locations along the migratory route (Lohmann and Lohmann, 1994; Lohmann and Lohmann, 1996; Lohmann et al., 2001; Putman et al., 2011; Fuxjager et al., 2011; Collett and Collett, 2011).

At any given time, the migratory trajectory of a turtle in the ocean is determined by a combination of two factors: movement due to swimming and movement attributable to ocean currents. Moreover, the speed of currents varies greatly among different parts of the Atlantic: in some areas, currents move more slowly than a young turtle can swim, whereas in others, they move several times faster (Revelles et al., 2007). Thus, although experimental results obtained under laboratory conditions provide valuable insight into guidance mechanisms, such findings alone cannot predict the degree to which navigational responses influence large-scale migratory movements.

In this study, we incorporated experimentally derived magnetic orientation behavior into a high-resolution ocean circulation model, so that we could simulate turtles' migratory trajectories and 
investigate how responses to regional magnetic fields affect them. The results demonstrate that a few simple navigational responses, expressed as small amounts of oriented swimming in response to regional magnetic fields, can have a disproportionately large effect on the migratory movements and the open-ocean distribution of turtles. The findings have important implications for numerous marine species traditionally assumed to depend entirely on ocean currents for transport.

\section{MATERIALS AND METHODS}

The duration of the pelagic migration of Florida loggerhead turtles is approximately 6-12 years (Bjorndal et al., 2000). In this study, we focused on the first part of the migration, during which turtles cross the Atlantic. Thus, our simulations were restricted to 5 year periods.

The movement of young turtles was simulated using the particle-tracking program ICHTHYOP v. 2.21 (Lett et al., 2008), which interpolated surface currents from the global Hybrid Coordinate Ocean Model (HYCOM) (Bleck, 2002). Global HYCOM is forced using wind stress, wind speed, heat flux and precipitation. Additionally, HYCOM uses data assimilation to produce 'hindcast' model output from satellite altimetry data and in situ measurements from a global array of expendable bathythermographs (XBTs), ARGO floats and moored buoys. We used the standard output, which has a spatial resolution of $0.08 \mathrm{deg}(\sim 7 \mathrm{~km})$ and a daily time step. Global HYCOM has been shown to accurately resolve mesoscale processes such as meandering currents, fronts, filaments and oceanic eddies (Bleck, 2002; Chassignet et al., 2007), which are important in realistically characterizing dispersal scenarios of turtles (Witherington, 2002; Bolten, 2003). For advection of particles through HYCOM velocity fields, ICHTHYOP implemented a Runge-Kutta fourthorder time-stepping method whereby particle position was calculated hourly (Lett et al., 2008). The study domain extended from the Equator to $47^{\circ} \mathrm{N}$ and from $100^{\circ} \mathrm{W}$ to the Prime Meridian (Fig. 1).
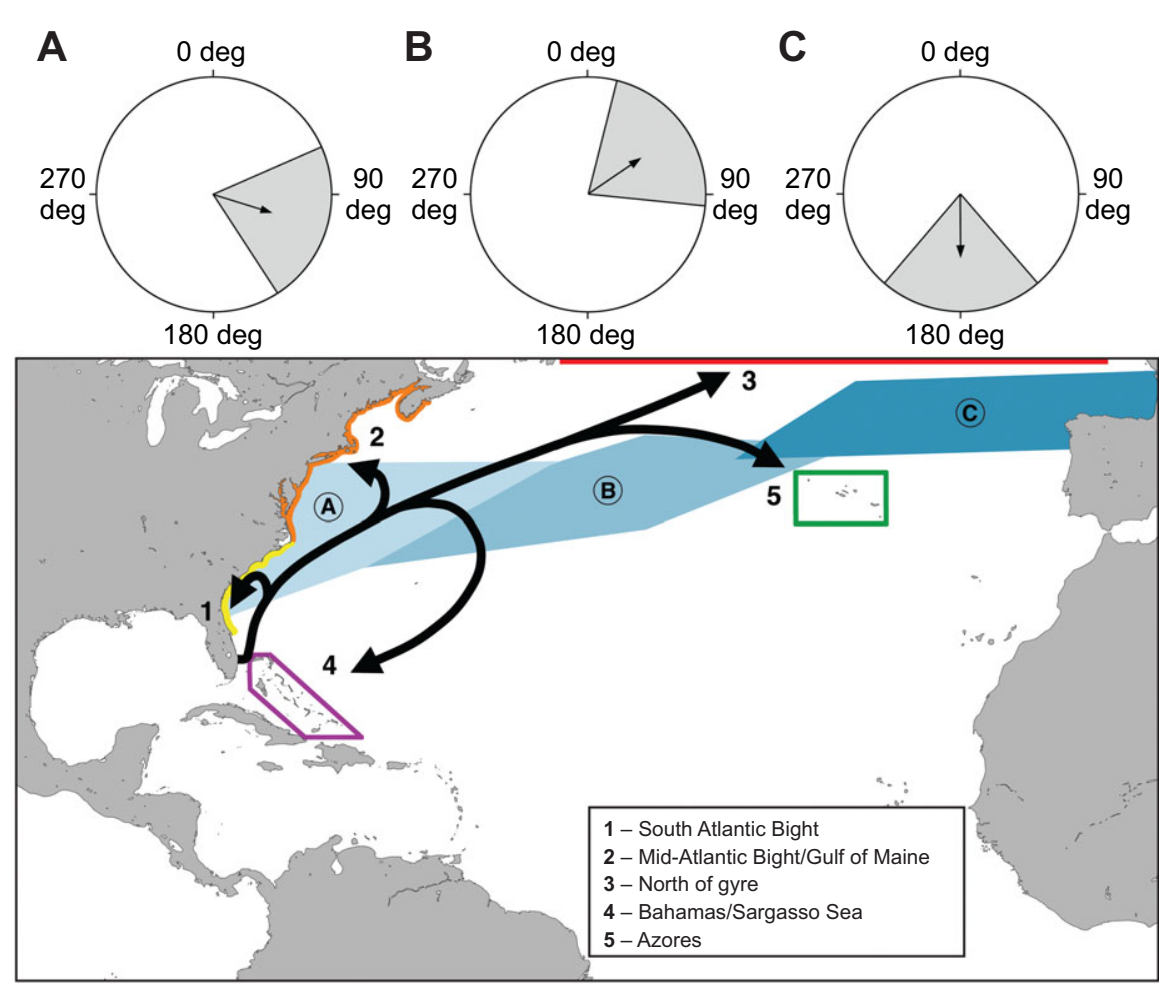

\section{Release conditions}

Virtual particles (i.e. simulated turtles) were released in an offshore zone that paralleled the east coast of Florida. The release zone was located between latitudes $26.0^{\circ} \mathrm{N}$ and $28.5^{\circ} \mathrm{N}$ and spanned an area that was $30-50 \mathrm{~km}$ from the coast. Releasing turtles offshore served to minimize the influence of coastal processes not characterized by the global HYCOM model. Moreover, $40 \mathrm{~km}$ (the center of the release zone) is the approximate distance that hatchling loggerheads can swim using the residual energy from their yolk sacks (Kraemer and Bennett, 1981); 30-50 km is also a distance from shore where post-hatchlings are routinely observed (Witherington, 2002).

Previous modeling studies on hatchling dispersal suggest that the interannual variation in ocean current conditions can greatly influence the outcome (Putman et al., 2010; Hays et al., 2010). To make our analysis as broadly applicable as possible and to avoid outcomes that result from conditions unique to any particular year, six different years were used as a starting point (2004-2009). Simulations starting in 2004 and 2005 ran through 2009 and 2010, respectively. Simulations starting in 2006, 2007, 2008 and 2009 ran through 2010 and then looped back over to resume in 2004. Therefore, in all simulations turtles were transported for a total of 5 years. For example, the simulation that began in 2006 ran until 2010 and then continued from 2004 to 2005. This 'looping technique' is common in oceanographic simulations (e.g. Brochier et al., 2009) and diminishes the potential impact of a single, anomalous year. Similarly, to reduce possible effects of storms or other unusual events that might yield atypical oceanic conditions, releases each year were at 5 day intervals starting on 1 July and continuing through 18 September, a period that encompasses the main loggerhead hatching season in Florida (Weishampel et al., 2003).

\section{Behavioral scenarios}

For each behavioral scenario modeled (Table 1), a total of 900,000 simulated turtles were tracked. This total consisted of 15 total release events of 1000 turtles each (see above), replicated 10 times each

Fig. 1. Possible dispersal routes of juvenile loggerheads migrating from southeast Florida, USA. Given surface currents in the North Atlantic, turtles can be transported along five main trajectories: (1) into the South Atlantic Bight (yellow coastline); (2) into the Mid-Atlantic Bight and the Gulf of Maine (orange coastline); (3) north of the subtropical gyre system (north of red line); (4) within the western portion of the Sargasso Sea around the Bahamas (purple polygon); or (5) to the eastern Atlantic passing through the Azores (green rectangle). Blue shaded regions (A-C) demarcate three 'navigation zones' defined by regional magnetic fields known to elicit navigational responses in young loggerheads (Lohmann et al., 2001; Fuxjager et al., 2011). Zones are irregularly shaped because of how the Earth's field varies across the Atlantic (see Materials and methods). The direction turtles swam in each navigation zone is shown by the gray-shaded area in the corresponding circular diagram. Each hour per day that a turtle swam, it adopted a new heading, randomly chosen from within this gray area. 
Table 1. Parameters of the four behavioral scenarios

\begin{tabular}{|c|c|c|c|c|c|}
\hline Behavior & $\begin{array}{l}\text { Swim duration } \\
\qquad\left(\text { h day }^{-1}\right)\end{array}$ & $\begin{array}{l}\text { Distance swum } \\
\qquad\left(\mathrm{km} \mathrm{day}^{-1}\right)\end{array}$ & $\begin{array}{l}\text { Swimming direction in } \\
\text { northwest navigation } \\
\text { zone (deg) }\end{array}$ & $\begin{array}{l}\text { Swimming direction in } \\
\text { north-central navigation } \\
\text { zone (deg) }\end{array}$ & $\begin{array}{c}\text { Swimming direction in } \\
\text { northeast navigation } \\
\text { zone (deg) }\end{array}$ \\
\hline Passive drifting & 0 & 0 & $\mathrm{n} / \mathrm{a}$ & $\mathrm{n} / \mathrm{a}$ & $\mathrm{n} / \mathrm{a}$ \\
\hline Magnetic navigation & 1 & 0.72 & $107 \pm 40$ & $55 \pm 40$ & $180 \pm 40$ \\
\hline Magnetic navigation & 2 & 1.44 & $107 \pm 40$ & $55 \pm 40$ & $180 \pm 40$ \\
\hline Magnetic navigation & 3 & 2.16 & $107 \pm 40$ & $55 \pm 40$ & $180 \pm 40$ \\
\hline \multicolumn{6}{|c|}{$\begin{array}{l}\text { Turtles either drifted passively or swam in response to regional magnetic fields for periods of } 1,2 \text {, or } 3 \mathrm{~h} \text { per day (see Materials and methods). The distance } \\
\text { that simulated turtles swam per day assumes movement in still water (no contribution of ocean currents). For simulations of swimming turtles, the three } \\
\text { swimming directions indicate the mean angle of orientation elicited by the magnetic field that defines each navigation zone (Fig. 1). Swimming direction is } \\
\text { based on data obtained by Lohmann et al. (Lohmann et al., 2001) and Fuxjager et al. (Fuxjager et al., 2011), corrected for average declination over each } \\
\text { navigation zone. For each hour that a turtle swam, a new directional heading was randomly assigned from a pool of headings within } 40 \text { deg of the mean } \\
\text { angle (see Materials and methods and Fig. 1). } \\
\text { n/a, not applicable. }\end{array}$} \\
\hline
\end{tabular}

year for each of six different years. Replications within each year differed in two parameters: (1) the exact release sites of individuals within the release zone, which were assigned randomly; and (2) the exact direction that individual turtles swam within each navigation zone, which was assigned randomly from a range of directions derived from empirical results (see below). The technique of tracking 900,000 simulated turtles in each of the behavioral scenarios allowed nearly all possibilities of transport to be observed and the use of statistics to determine the likelihood of each possibility.

Modifications were made to ICHTHYOP to simulate the swimming behavior of young turtles. For the active swimming scenarios, three geographic regions along the northern portion of the turtles' migratory route were designated as 'navigation zones' (Fig. 1). Each zone encompassed the location of a specific magnetic field that is known to elicit directional swimming in loggerhead hatchlings (Lohmann et al., 2001; Fuxjager et al., 2011). The magnetic fields were defined by intensity (field strength) and inclination (the angle at which field lines intersect the Earth's surface) and correspond to broad oceanic regions in the northwest, north-central and northeastern Atlantic (Fig. 1, Table 1). Because the precise boundaries of each navigation zone have not been determined empirically, we arbitrarily extended each zone outward $\pm 3.0 \mu \mathrm{T}$ of intensity and $\pm 3.0 \mathrm{deg}$ inclination (or until this extrapolation brought the zone into contact with an adjacent navigation zone). This process yielded navigation zones that were wider in the east-west axis than in the north-south axis (Fig. 1), a pattern attributable to the fact that the magnetic field in the North Atlantic varies more with latitude than with longitude (Putman et al., 2011).

In simulations, turtles were transported passively by currents unless they entered one of the three navigation zones, at which point additional velocity was imparted to them in a direction that depended on the zone (see below). When in a navigation zone, simulated turtles swam $0.20 \mathrm{~m} \mathrm{~s}^{-1}$, a speed that both hatchlings and juveniles are capable of sustaining (O'Hara, 1980; Salmon and Wyneken, 1987; Revelles et al., 2007). The duration of swimming bouts varied among scenarios and included $1 \mathrm{~h}$ per day (total distance traveled under the turtles' own power in still water $=0.72 \mathrm{~km}$ per day), $2 \mathrm{~h}$ per day (distance $=1.44 \mathrm{~km}$ per day) and $3 \mathrm{~h}$ per day (distance $=2.16 \mathrm{~km}$ per day). These swim durations and corresponding distances are well within the physiological capabilities of young loggerheads (O'Hara, 1980; Kraemer and Bennett, 1981; Salmon and Wyneken, 1987; Revelles et al., 2007). These conservative estimates were selected to avoid overestimating the influence of navigation behavior on turtle distributions.

Four behavioral scenarios were modeled (Table 1). One assumed that turtles drifted passively. Three other scenarios assumed that turtles swam 1, 2 or $3 \mathrm{~h}$ per day. The directions that turtles swam matched those of actual turtles that were tested in the same magnetic fields that defined each of the navigation zones (Lohmann et al., 2001; Fuxjager et al., 2011). At the start of every hour that a simulated turtle swam, a directional heading was assigned. The heading was selected randomly from a range of orientation bearings suitable for each navigation zone. All headings in a given zone were within \pm 40 deg of the mean heading elicited by the corresponding field. The $80 \mathrm{deg}$ range of orientation angles used approximately matches the $95 \%$ confidence interval observed in behavioral experiments (Lohmann et al., 2001; Fuxjager et al., 2011). Turtles only swam when inside a navigation zone (Fig. 1); otherwise they drifted passively. We initially included simulations of turtles that swam for equivalent periods ( $1-3 \mathrm{~h}$ per day) in random directions (0-359 deg), but do not report these results here because outcomes were essentially identical to those of the passively drifting group (supplementary material Fig. S1). Parameters for each behavioral scenario are summarized in Table 1.

\section{Analyses}

As a first step towards visualizing how navigation behavior might affect the distribution of young loggerheads throughout the North Atlantic, we generated maps that highlight locations where models of passive drift and oriented swimming behavior predicted differences in abundance. For each 5 year period modeled, one of the 10 replicates of passive drifting and one of the 10 replicates of magnetic navigation were selected at random. An image showing the distribution of turtles in each scenario was created by plotting the locations of all turtles at 25 day intervals starting 18 September and continuing through the duration of the simulation. This date was chosen as a starting point because that was when the final group of simulated hatchlings was released each year and thus was the first day that the position of all turtles could be plotted. In each image, individual turtles were represented as squares of approximately $0.25^{\circ}$ latitude by $0.25^{\circ}$ longitude, centered on the exact position specified by ICHTHYOP. A custom Python ${ }^{\mathrm{TM}}$ script summed the number of turtles overlapping each pixel in the map.

This process was repeated for both maps, so that each pixel in each map was assigned a value representing the number of turtles at that geographic location. For each pixel, the script then subtracted the value obtained in the magnetic navigation simulation from the value obtained in the passive drift simulation. These data were used to generate a new map, in which negative values (highlighted in blue) corresponded to locations where navigation behavior led to an increased density of turtles and positive values (highlighted in red) corresponded to locations where navigation behavior led to a 


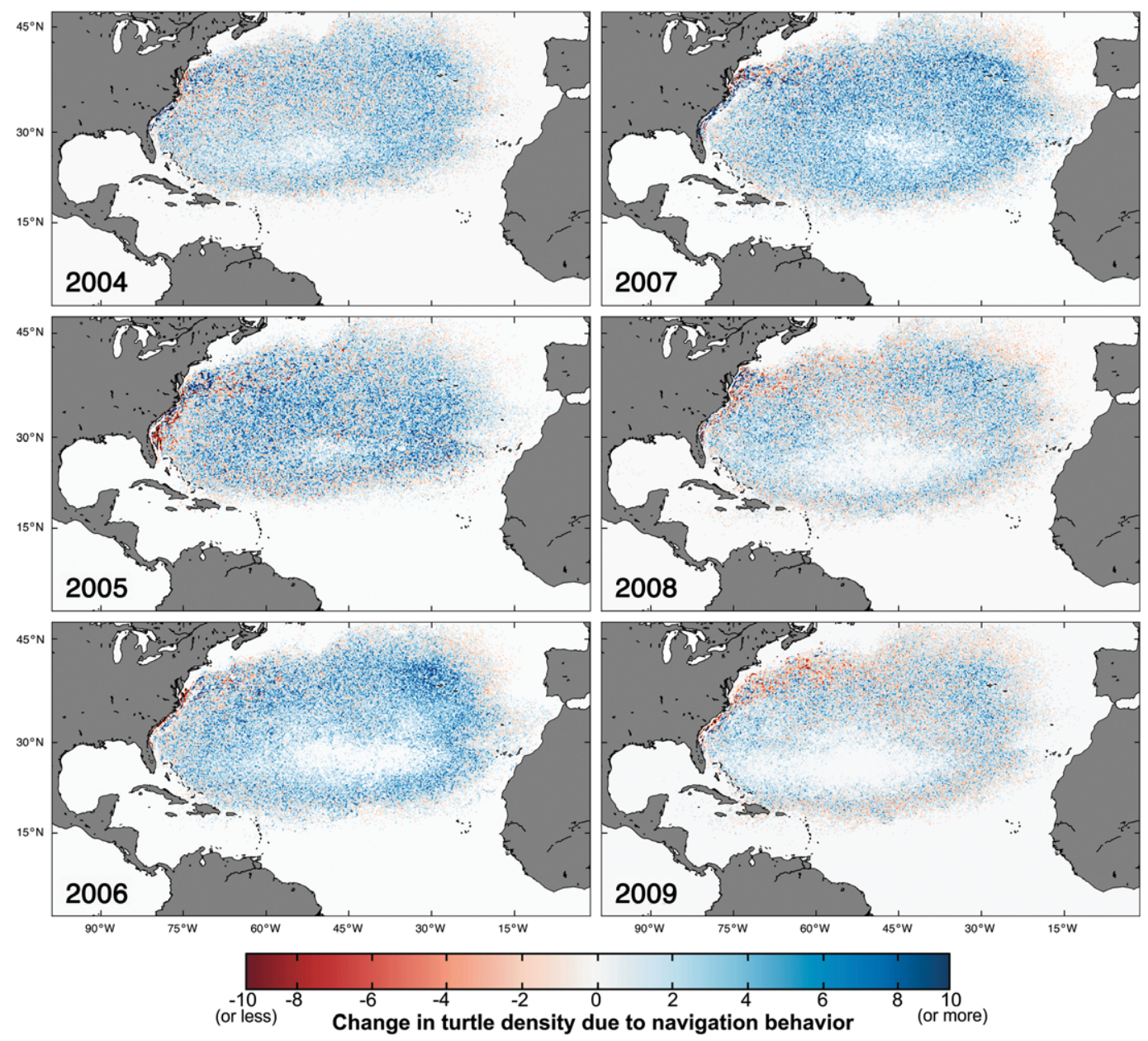

Fig. 2. Effects of simulated magnetic navigation behavior on spatial patterns of loggerhead turtle abundance in the North Atlantic. Each map displays the results of a different 5 year period (the start year is indicated in the lower left corner) in which the distribution of turtles that drifted passively was compared with the distribution of turtles that engaged in $2 \mathrm{~h}$ of magnetic navigation behavior per day. Locations highlighted in blue correspond to areas where navigation behavior (see Materials and methods) led to an increased abundance of turtles relative to passive drift. Locations in red correspond to areas where the same navigation behavior led to a decrease in the abundance of turtles relative to passive drift. The darker each color, the greater the difference in predicted turtle density between simulations involving navigation behavior and those involving passive drift. Locations with no difference in predicted turtle density between the two scenarios are colored white (indicated by 0 on the color scale at the bottom of the figure). Most blue coloration is distributed within the currents of the North Atlantic Subtropical Gyre (a favorable habitat for young loggerheads), indicating that magnetic navigation increases turtle density (relative to passive drift) in this oceanic area. In particular, a dense cluster of blue can be seen around the Azores (islands off the coast of Portugal; see Fig. 1, trajectory 5 for location) during most 5 year periods, suggesting that responses to regional magnetic fields facilitate migration to this productive foraging area. For all six years studied, magnetic navigation led to an increase in the number of turtles reaching the Azores relative to passive drifters: $110 \%$ in $2004,117 \%$ in $2005,122 \%$ in $2006,141 \%$ in $2007,75 \%$ in 2008 and $57 \%$ in 2009 . By contrast, red coloration is mostly concentrated near the margins of the gyre. Thus, relative to passive drift, magnetic navigation apparently diminished the density of turtles in suboptimal locations where predation or winter temperatures pose risk, such as along the eastern US coast and in the northeastern corner of the gyre.

decreased density of turtles. Color scales were adjusted so that darker colors indicated greater differences in turtle density between the two scenarios. In other words, dark blue indicated a location where navigation behavior greatly increased turtle density, relative to the scenario of passive drift, whereas light blue indicated only a modest increase (see color scale in Fig. 2). Locations with no difference between behavioral scenarios were shown as white. For simplicity, we present the results comparing the simulations of passive drift to the intermediate activity level that was modeled $(2 \mathrm{~h}$ per day of swimming).

To further quantify how magnetic navigation behavior of young loggerheads influences their distribution in the North Atlantic, we performed statistical analyses using the data from all 10 replicates per simulation and for each behavioral scenario. To determine the percentage of turtles following five likely dispersal trajectories, we counted the number of turtles throughout the 5 year simulations that entered: (1) the South Atlantic Bight; (2) the Mid-Atlantic Bight and Gulf of Maine; (3) any area north of $46^{\circ}$ latitude; (4) the waters surrounding the Bahamas; and (5) the waters surrounding the Azores (Fig. 1). These five trajectories differ in their suitability for young turtles. The first three trajectories (South Atlantic Bight, MidAtlantic Bight/Gulf of Maine and north of $46^{\circ}$ latitude) are likely suboptimal because winter temperatures fall below the thermal tolerance of loggerheads (Collard and Ogren, 1990; Witt et al., 2010). Additionally, predators of young turtles are thought to be abundant in coastal waters of North America and the likelihood of small turtles surviving in such areas is probably low (Collard and Ogren, 1990; Whelan and Wynken, 2007). In contrast, the opensea trajectories that lead towards the Bahamas and Azores have appropriate temperatures, ample foraging opportunities and reduced 
predation risk and are thus favorable for young loggerheads (Carr, 1986; Carr, 1987; Bolten and Bjorndal, 1988; Bjorndal and Bolten, 1988; Bolten et al., 1998).

A two-way ANOVA with replication was used to determine whether magnetic navigation behavior influences the proportion of turtles following the five dispersal trajectories in the North Atlantic throughout the 5 year simulations. The two factors we considered were swimming activity (d.f.=3) and dispersal trajectory (d.f.=4). For each swimming activity $(0,1,2,3 \mathrm{~h}$ per day of swimming), we calculated the mean percentage of turtles that followed each trajectory in the 10 replicates (thus the six 5 year periods were treated as replicates). Two-way ANOVAs with replication were also used to determine whether swimming activity affected the percentage of turtles that followed different dispersal trajectories. For these analyses, the two factors were swimming activity (d.f.=3) and the six 5 year periods (d.f. $=5$ ); in this case the 10 replicates for each 5 year period served as replicates.

At present, no empirical observations of loggerhead abundance in the open ocean are available to compare with the predicted patterns from these models. However, as a first step towards determining which modeled behavior is most compatible with the available data on the open-sea distribution of loggerheads, we compared the results for each behavioral scenario with analyses by Monzon-Arguello et al. (Monzon-Arguello et al., 2009), which used mtDNA to predict the connectivity between the nesting rookeries and foraging grounds of loggerheads in the North Atlantic. Their techniques took into account the relative population sizes at nesting rookeries and the haplotype frequencies at the rookeries and foraging grounds to generate a 'rookery-centric' estimate of the percentage of turtles from a given rookery that travel to particular foraging grounds. Because of our focus on navigation behavior along the northern portion of the turtles' migratory route, we compared the percentage of simulated turtles reaching the Azores in our model with the estimate by Monzon-Arguello et al. (Monzon-Arguello et al., 2009) for the south Florida loggerhead rookery. To make our results comparable, we excluded from this analysis turtles that: (1) were advected into coastlines [as was done by Blumenthal et al. (Blumenthal et al., 2009)]; and (2) exited the domain north of $47^{\circ}$ latitude during the first year of the simulation. This was necessary because ICHTHYOP (v. 2.21) particle-tracking software does not compute subsequent trajectories for such particles that, in effect, experience 'mortality'. The technique used by Monzon-Arguello et al. (Monzon-Arguello et al., 2009) does not consider mortality and assumes that all turtles from a given rookery survive to reach some location (even if the location is unknown) (Bolker et al., 2007).

\section{RESULTS}

\section{Basin-scale patterns of abundance}

Compared with scenarios of passive drift, magnetic navigation behavior increased the number of simulated turtles entering and remaining within the main currents of the North Atlantic Subtropical Gyre (Fig. 2), an area favorable for the growth and survival of young loggerheads (Carr, 1986; Carr, 1987; Bolten, 2003). In particular, more turtles that engaged in magnetic navigation were present in the productive waters around the Azores than were turtles that drifted passively. Moreover, magnetic navigation led to a decrease in the number of turtles along the western and northeastern margins of the gyre (Fig. 2). Such locations are likely suboptimal for young turtles because of increased risk of predation [e.g. along the eastern coast of North America (Whelan and Wyneken, 2007)] and lethally cold winter temperatures [e.g. the northeastern corner of the gyre and the eastern coast of North America (Witt et al., 2010)].

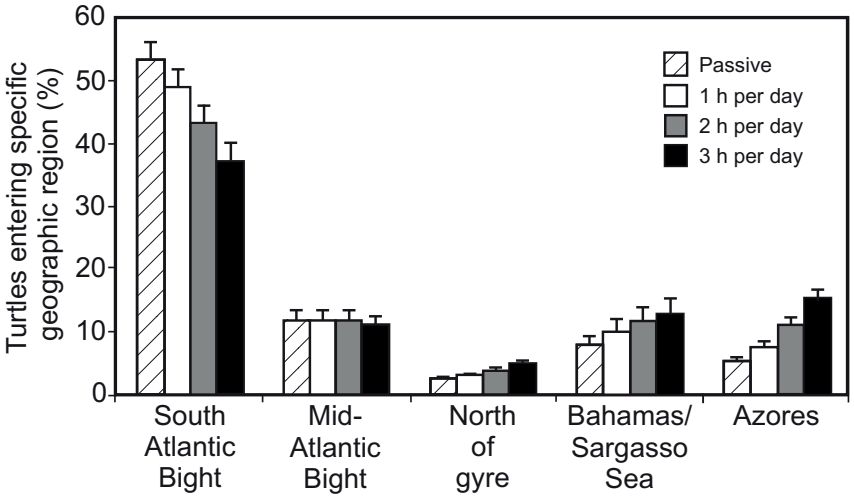

Fig. 3. Mean percentages of simulated turtles entering specific geographic regions within 5 years. Regions correspond to the trajectories shown in Fig. 1: (1) South Atlantic Bight, (2) Mid-Atlantic Bight, (3) north of gyre, (4) Bahamas/Sargasso Sea, and (5) Azores. Hatched bars indicate results from simulated turtles that drifted passively. White bars indicate results obtained from simulated turtles that engaged in $1 \mathrm{~h}$ of oriented swimming per day, gray bars indicate $2 \mathrm{~h}$ of oriented swimming per day, and black bars indicate $3 \mathrm{~h}$ of oriented swimming per day. Error bars indicate 95\% confidence intervals of the mean.

\section{Dispersal trajectories}

ANOVA analyses indicated that the relative proportions of turtles that followed the various trajectories (Fig. 1) differed significantly depending on the behavior that was simulated (two-factor ANOVA, $F_{4,3}=101, P=2.86 \times 10^{-34}$; Fig. 3 ). Across all six periods modeled, magnetic navigation led to a decrease in the number of turtles following the trajectory to the South Atlantic Bight (two-factor ANOVA, $F_{3,5}=37.3, P=3.34 \times 10^{-7}$ ). There was no net effect of magnetic navigation behavior on the number of turtles entering the Mid-Atlantic Bight and Gulf of Maine (two-factor ANOVA, $\left.F_{3,5}=0.089, P=0.965\right)$. There was a slight increase in the number of turtles that encountered latitudes north of the gyre as modeled swim duration increased (two-factor ANOVA, $F_{3,5}=10.2, P=6.52 \times 10^{-4}$; Fig. 3). This effect was likely attributable to fewer turtles remaining along the North American coast when swimming was simulated (Fig. 2); thus an increased number of turtles were carried eastward by the Gulf Stream and subsequently encountered currents that branch off northwards from the gyre.

Magnetic navigation behavior led to increases in the percentage of simulated turtles entering the oceanic regions near the Bahamas (two-factor ANOVA, $F_{3,5}=14.5, P=1.02 \times 10^{-4}$ ) and the Azores (twofactor ANOVA, $F_{3,5}=24.3, P=5.16 \times 10^{-6}$; Fig. 3 ), two areas likely to be suitable developmental habitat for young loggerheads (Carr, 1986; Carr, 1987; Bolten and Bjorndal, 1988; Bjorndal and Bolten, 1988; Bolten et al., 1998). Results further indicate that, although navigation behavior did not prevent all turtles from entering suboptimal oceanic regions (Fig. 3), it is likely to help turtles escape from such areas to resume their open-sea migration (Fig.4). For example, among turtles that entered the South Atlantic Bight, those that swam just $1 \mathrm{~h}$ per day were $214 \%$ more likely to reach the Azores than were those that drifted passively. Greater amounts of swimming further increased the likelihood of escaping these coastal waters and arriving at the Azores (by $542 \%$ for turtles that swam $2 \mathrm{~h}$ per day and $1418 \%$ for those that swam $3 \mathrm{~h}$ per day) (Fig. 4A). Similarly, turtles that entered the Mid-Atlantic Bight but swam 1-3h per day were $25-101 \%$ more likely to reach the Azores than were passive drifters (Fig. 4B), and turtles that crossed latitudes north of $46^{\circ} \mathrm{N}$ were $5-25 \%$ more likely to arrive at the Azores if they swam (Fig. 4C). 


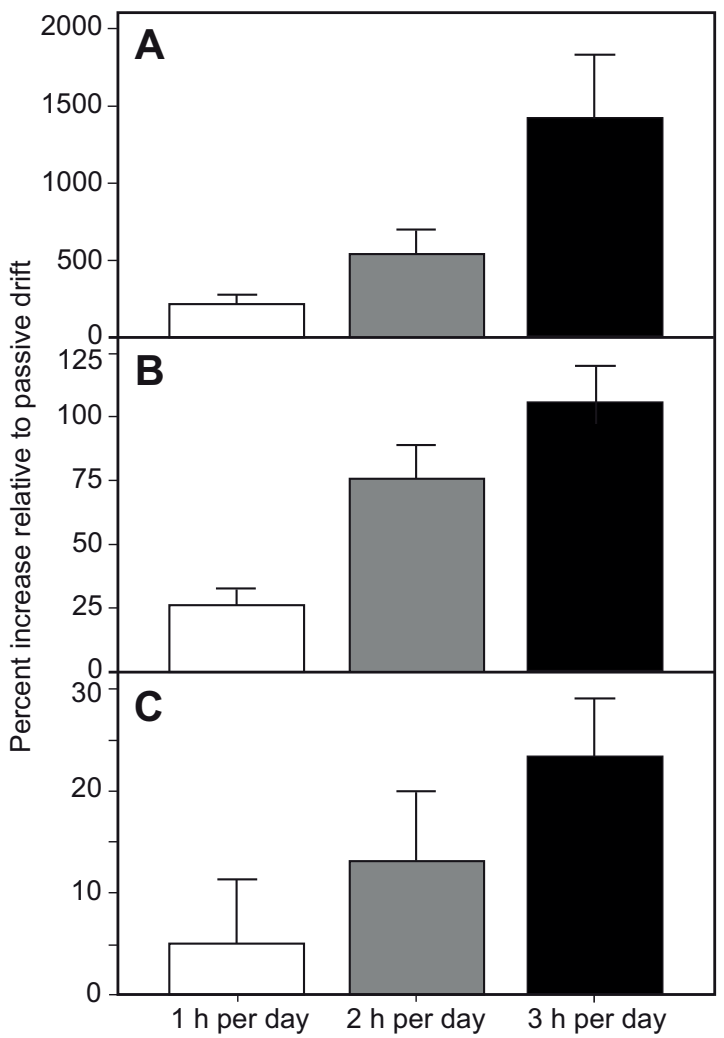

Fig. 4. Graph showing the effects of directional swimming behavior on outcomes for simulated turtles that enter suboptimal oceanic regions: $(A)$ South Atlantic Bight (trajectory 1), (B) Mid-Atlantic Bight/Gulf of Maine (trajectory 2) and $(C)$ north of the gyre (trajectory 3; Fig. 1). The white bars indicate the mean percent increase of simulated turtles reaching the productive waters of the Azores given $1 \mathrm{~h}$ of swimming per day as compared with passive drifting. Gray bars correspond to $2 \mathrm{~h}$ of swimming per day, and black bars correspond to $3 \mathrm{~h}$ of swimming per day. Error bars represent $95 \%$ confidence intervals of the mean.

\section{Comparison with mixed-stock genetics estimate of juvenile loggerheads in the Azores}

Simulations of passive drift estimated that $17.3 \%$ of turtles that survive their first year reach the Azores within 5 years. Simulations that assumed 1, 2 and $3 \mathrm{~h}$ of magnetic navigation per day resulted in estimates of 20.2, 22.7 and $26.8 \%$ of turtles reaching the Azores, respectively (Fig. 5). The genetic analyses by Monzon-Arguello et al. (Monzon-Arguello et al., 2009) estimated that 29.6\% of loggerheads from the south Florida rookery reach the Azores Islands. This comparison suggests that the magnetic navigation behavior modeled ( $3 \mathrm{~h}$ per day of oriented swimming) is more consistent with what is presently known about loggerhead distributions in the North Atlantic than scenarios of passive drift.

\section{DISCUSSION}

Our results suggest that young turtles can exert considerable influence on their migratory trajectories despite swimming at velocities much slower than those of many ocean currents (Figs 2, $3,5)$. A simple navigational strategy, in which a few regional magnetic fields elicit directional swimming, greatly increased the probability of simulated turtles reaching habitats favorable for growth and development, while simultaneously reducing the likelihood of turtles entering or remaining in suboptimal geographic areas (Figs 2, 3, 5). These effects were observed despite a set of

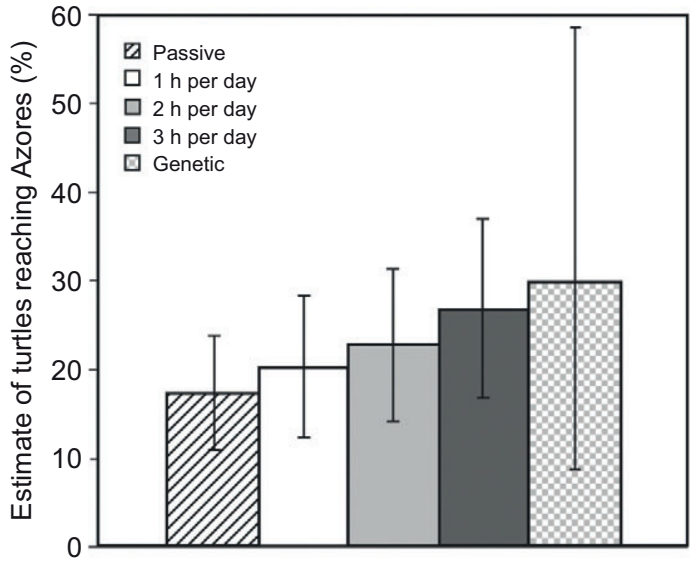

Fig. 5. Estimates for the percentage of loggerhead turtles entering the waters around the Azores Islands based on simulated dispersal (this paper) and genetic analyses (Monzon-Arguello et al., 2009). Hatched bars indicate results from simulated turtles that drifted passively. White bars indicate results obtained from simulated turtles that engaged in $1 \mathrm{~h}$ of oriented swimming per day, light gray bars indicate $2 \mathrm{~h}$ of oriented swimming per day, and dark gray bars indicate $3 \mathrm{~h}$ of oriented swimming per day. Bars with the gray and white checkerboard pattern indicate the rookery-centric many-to-many estimate from genetic analyses (Monzon-Arguello et al., 2009). Error bars indicate the $95 \%$ confidence intervals of the mean. See Materials and methods for details on calculations. Of the particle-tracking simulations run, the closest agreement with the estimate from genetic mixed-stock analysis assumed that turtles engaged in $3 \mathrm{~h}$ per day of oriented swimming in response to regional magnetic fields.

conservative assumptions, such as that turtles engage in only brief periods of swimming (1-3h per day while in 'navigation zones'), that they travel distances of no more than $0.72-2.16 \mathrm{~km}$ per day (Table 1), that they only swim in response to three regional magnetic fields along the northern edge of the gyre, and that they are only weakly oriented $[ \pm 40 \mathrm{deg}$ of mean direction, as in laboratory experiments (Lohmann et al., 2001; Fuxjager et al., 2011)]. Our findings call for a reassessment of the theory that small turtles are powerless to influence their dispersal trajectories, and that their distribution on a basin-wide scale is completely dependent on ocean currents (Carr, 1987; Collard and Ogren, 1990; Luschi et al., 2003; Hays et al., 2010; Okuyama et al., 2011).

These simulations imply that, rather than relying on an energetically costly strategy of continuous swimming, turtles can advance along the migratory route with relative ease by using limited directional swimming to help them become entrained in currents that will carry them to appropriate oceanic regions. Behavioral experiments also suggest that the headings adopted by turtles in response to each regional field have evolved to take advantage of surface circulation patterns of the North Atlantic Subtropical Gyre (Lohmann et al., 2012; Putman et al., 2011; Fuxjager et al., 2011).

In some cases, the advantages that result from a small amount of directional swimming are likely to be considerable. For example, among turtles that entered the predator-rich South Atlantic Bight, those that engaged in oriented swimming were up to 14 times more likely to reach the Azores than turtles that drifted passively (Fig. 4A). An additional advantage of oriented swimming, as proposed by Scott et al. (Scott et al., 2011), is that turtles along the northern gyre boundary may grow more rapidly as a result of swimming south into warmer waters.

These and related findings (Figs 2-4) imply that magnetic navigation behavior might have substantial adaptive value. If so, 

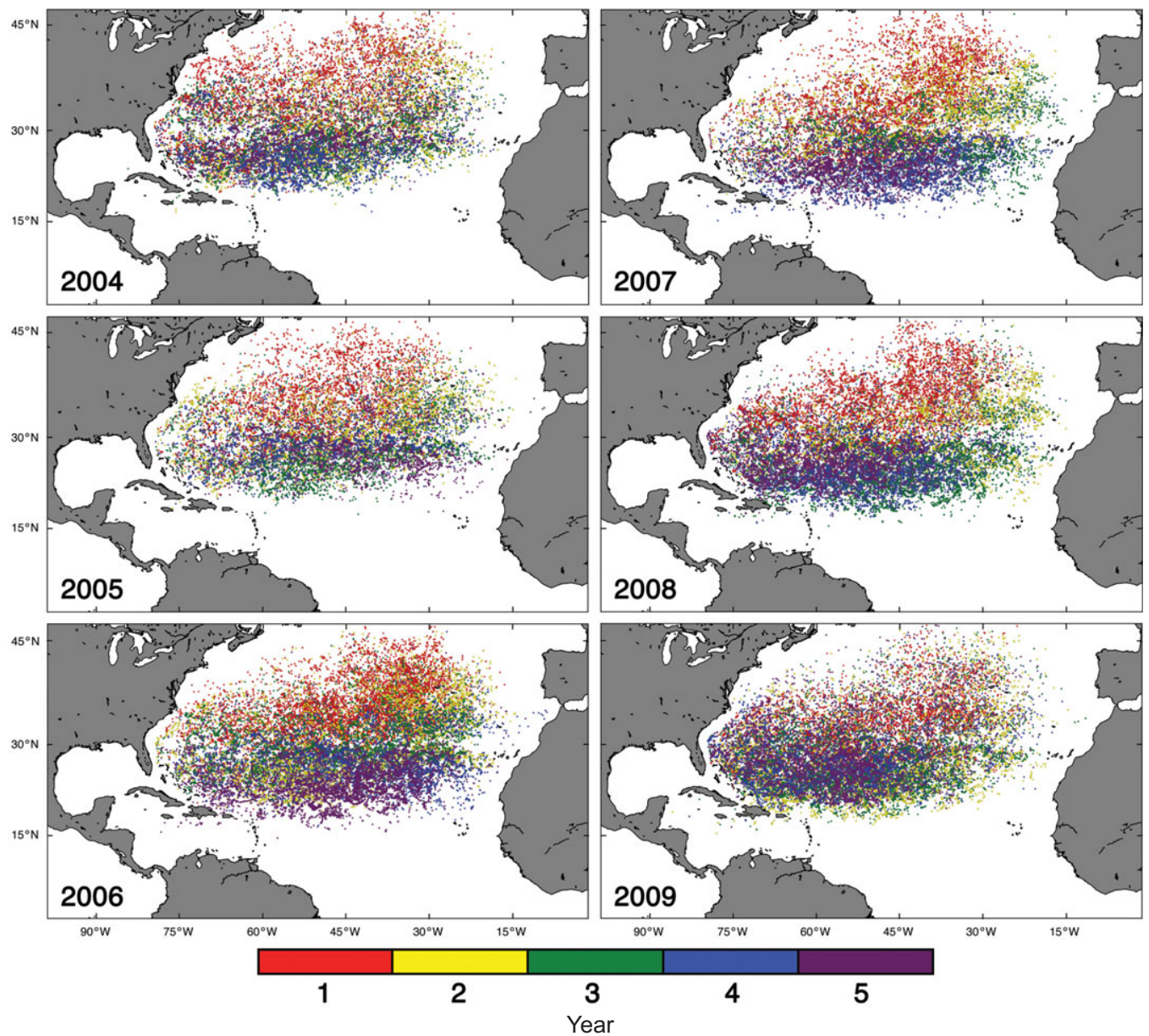

Fig. 6. Distribution of simulated turtles that swam $2 \mathrm{~h}$ per day in response to regional magnetic fields. Locations of turtles are shown at 1 year intervals for each of the 5 year periods simulated. Red dots indicate the locations of turtles at the end of the first year, yellow the locations at the end of the second year, green the locations at the end of the third year, blue the locations at the end of the fourth year, and purple locations at the end of the fifth year. Turtles tend to be distributed in more northerly locations in the first year and more southerly by the fifth year; even so, colors are fairly well mixed throughout much of the North Atlantic. One limitation of these simulations is that they modeled only oriented swimming in response to three regional magnetic fields along the northern boundary of the gyre, whereas responses to fields elsewhere in the gyre may also modify turtles' distribution in the open ocean (Lohmann et al., 2012). Nevertheless, these results suggest that there is considerable variation in the dispersal trajectories that young loggerheads are likely to follow (including for those hatched in the same season). Similarly, the time that it takes to complete the transoceanic migration, or to arrive at a particular region along the way, varies greatly among individuals. The unpredictable nature of the environment in which turtles migrate appears to have selected for a navigation system comprised of location-dependent responses, in which turtles respond to specific regional magnetic fields that exist in particular geographic areas if and when they encounter them.

then such behavior is likely to be strongly favored by natural selection and, once it arises, will presumably spread rapidly through a population. Similarly, as Earth's magnetic field gradually changes over time, strong selective pressure is likely to ensure that the navigation responses of turtles evolve in parallel with the changing field, so that fields that exist along the migratory route consistently elicit orientation that facilitates movement toward favorable oceanic regions (Lohmann et al., 2001; Lohmann and Lohmann, 2003; Lohmann et al., 2007).

These simulations are also consistent with the hypothesis that there is considerable variation in the migratory pathways of young loggerheads (Fig. 1) (Bolten, 2003; Lohmann et al., 2012). Hatchling turtles leaving the same beaches during the same year may follow very different trajectories and reach very different locations (Fig. 6). For example, a hatchling that remains in the center of the Gulf Stream may be carried rapidly across the Atlantic (trajectory 5 in Fig. 1), whereas a hatchling on the eastern side of the current may be carried initially toward the Bahamas (trajectory 4 in Fig. 1) before rejoining the Gulf Stream. As a result, the time that it takes to complete the transoceanic migration, or to arrive at a particular region along the way, is likely to vary greatly among individuals (Fig. 6). Given these uncertainties, there are clear advantages to a navigational system comprised of location-dependent responses, in which turtles respond to specific regional fields that exist in particular geographic areas if and when they encounter them.

To date, most attempts to model the pelagic dispersal of sea turtles have assumed that turtles drift passively (e.g. Hays and Marsh, 1997; Blumenthal et al., 2009; Godley et al., 2010; Hays et al., 2010; Putman et al., 2010; Okuyama et al., 2011). Although models of passive drift can provide a useful first step towards understanding large-scale patterns of distribution, our results demonstrate that including empirically derived navigational behavior of sea turtles in particle-tracking models can greatly alter predicted patterns of abundance (Fig.2). Therefore, models that assume passive drift should be interpreted with caution. In particular, such models may not yield accurate estimates of the contributions that specific nesting populations make to distant mixed-stock foraging grounds or other geographic areas. For instance, of the particle-tracking simulations 
that we ran, the best agreement with the estimate from genetic mixedstock analysis for the percentage of south Florida turtles reaching the Azores (Monzon-Arguello et al., 2009) assumed that turtles engaged in $3 \mathrm{~h}$ per day of swimming in response to regional magnetic fields (Fig. 6). Thus, incorporating empirically derived navigation behavior into models of dispersal is likely to provide more realistic predictions of animal distributions, as well as an improved understanding of the physiological, ecological and evolutionary processes shaped by animal movement (Werner et al., 1993; Paris et al., 2007; Holyoak et al., 2008).

Finally, the finding that young turtles can exert an unexpectedly strong influence on their migratory movements has important implications for diverse, weakly swimming marine animals such as larval eels (McCleave et al., 1998; Bonhommeau et al., 2009), juvenile salmon (Azumaya and Ishida, 2001), juvenile haddock and cod (Werner et al., 1993), juvenile reef fish (Paris et al., 2007) and invertebrate larvae (Jeffs et al., 2005). Such migrants, whose movements have often been assumed to be dictated exclusively by currents might, in fact, employ strategies similar to those of young loggerheads in order to improve the likelihood of reaching appropriate habitat.

\section{ACKNOWLEDGEMENTS}

We thank J. M. Bane, T. Kristiansen, C. M. F. Lohmann and E. M. Putman for comments and suggestions.

\section{FUNDING}

Funding for this research was provided by the National Science Foundation [grants IOS-0718991 and IOS-1022005 to K.J.L.], and the PADI Foundation and the Lerner-Gray Fund for Marine Research [to N.F.P.].

\section{REFERENCES}

Akesson, S. and Hedenstrom, A. (2007). How migrants get there: migratory performance and orientation. BioScience 57, 123-133.

Alerstam, T. (2006). Conflicting evidence about long-distance animal navigation. Science 313, 791-794.

Azumaya, T. and Ishida, Y. (2001). Effects of ocean currents on juvenile chum salmon migration. NPAFC Tech. Rep. 2, 17-19.

Bjorndal, K. A. and Bolten, A. B. (1988). Growth rates of juvenile loggerheads, Caretta caretta, in the southern Bahamas. J. Herpetol. 22, 480-482.

Bjorndal, K. A., Bolten, A. B. and Martins, H. R. (2000). Somatic growth model of juvenile loggerhead sea turtles Caretta caretta: duration of pelagic stage. Mar. Ecol. Prog. Ser. 202, 265-272.

Bleck, R. (2002). An oceanic general circulation model framed in hybrid isopycnic Cartesian coordinates. Ocean Modeling 4, 55-88.

Blumenthal, J. M., Abreu-Grobois, F. A., Austin, T. J., Broderick, A. C., Bruford, M. W., Coyne, M. S., Ebanks-Petrie, G., Formia, A., Meylan, P. A., Meylan, A. B. et al. (2009). Turtle groups or turtle soup: dispersal patterns of hawksbill turtles in the Caribbean. Mol. Ecol. 18, 4841-4853.

Bolker, B. M., Okuyama, T., Bjorndal, K. A. and Bolten, A. B. (2007). Incorporating multiple mixed stocks in mixed stock analysis: 'many-to-many' analyses. Mol. Ecol. 16, 685-695.

Bolten, A. B. (2003). Active swimmers - passive drifters. In Loggerhead Sea Turtles (ed.

A. B. Bolten and B. E. Witherington), pp. 63-78. Washington, DC: Smithsonian Institution Press.

Bolten, A. B. and Bjorndal, K. A. (1988). Growth rates of immature green turtles, Chelonia mydas, on feeding grounds in the southern Bahamas. Copeia 1988, 555-564.

Bolten, A. B., Bjorndal, K. A., Martins, H. R., Dellinger, T., Biscoito, M. J., Encalada,

S. and Bowen, B. W. (1998). Transatlantic developmental migrations of loggerhead sea turtles demonstrated by mtDNA sequence analysis. Ecol. Appl. 7, 1-7.

Bonhommeau, S., Le Pape, O., Gascuel, D., Blanke, B., Tréguier, A. M., Grima, N., Vermard, Y., Castonguay, M. and Rivot, E. (2009). Estimates of the mortality and the duration of the trans Atlantic migration of European eel Anguilla anguilla leptocephali using a particle tracking model. J. Fish Biol. 74, 1891-1914.

Boyer, D. and Walsh, P. D. (2010). Modelling the mobility of living organisms in heterogeneous landscapes: does memory improve foraging success? Philos. Trans. $R$. Soc. Lond. A 368, 5645-5659.

Brochier, T., Colas, F., Lett, C., Echevin, V., Cubillos, L. A., Tam, J., Chlaida, M., Mullon, C. and Fréon, P. (2009). Small pelagic fish reproductive strategies in upwelling systems: a natal homing evolutionary model to study environmental constraints. Prog. Oceanogr. 83, 261-269.

Carr, A. F. (1986). Rips, FADS and little loggerheads. Bioscience 36, 92-100.

Carr, A. F. (1987). New perspectives on the pelagic stage of sea turtle development. Conserv. Biol. 1, 103-121.

Chassignet, E. P., Hurlburt, H. E., Smedstad, O. M., Halliwell, G. R., Hogan, P. J., Wallcraft, A. J., Baraille, R. and Bleck, R. (2007). The HYCOM (HYbrind Coordinate Ocean Model) data assimilative system. J. Mar. Syst. 65, 60-83.
Collard, S. B. and Ogren, L. H. (1990). Dispersal scenarios for pelagic post-hatchling sea turtles. Bull. Mar. Sci. 47, 233-243.

Collett, T. S. and Collett, M. (2011). Animal navigation: following sign-posts in the sea. Curr. Biol. 21, R843-R846.

Dingle, H. (1996). Migration: The Biology of Life on the Move. New York: Oxford University Press.

Fuxjager, M. J., Eastwood, B. S. and Lohmann, K. J. (2011). Orientation of hatchling loggerhead sea turtles to regional magnetic fields along a transoceanic migratory pathway. J. Exp. Biol. 214, 2504-2508.

Godley, B. J., Barbosa, C., Bruford, M., Broderick, A. C., Catry, P., Coyne, M. S., Angela, F., Hays, G. C. and Witt, M. J. (2010). Unraveling migratory connectivity in marine turtles using multiple methods. J. Appl. Ecol. 47, 769-778.

Gould, J. L. (2011). Animal navigation: longitude at last. Curr. Biol. 21, R25-R27.

Hays, G. C. and Marsh, R. (1997). Estimating the age of juvenile loggerhead sea turtles in the North Atlantic. Can. J. Zool. 75, 40-46.

Hays, G. C., Fossette, S., Kastelidis, K. A., Mariani, P. and Schofield, G. (2010). Onogenetic development of migration: Lagrangian drift trajectories suggest a new paradigm for sea turtles. J. R. Soc. Interface 7, 1319-1327.

Holyoak, M., Casagrandi, R., Nathan, R., Revilla, E. and Spiegel. O. (2008). Trends and missing parts in the study of movement ecology. Proc. Natl. Acad. Sci. USA 105 19060-19065.

Jeffs, A. G., Montgomery, J. C. and Tindle, C. T. (2005). How do spiny lobster postlarvae find the coast? N. Z. J. Mar. Freshw. Res. 39, 605-517.

Kraemer, J. E. and Bennett, S. H. (1981). Utilization of posthatchling yolk in loggerhead sea turtles (Caretta caretta). Copeia 1981, 406-411.

Lett, C., Verley, P., Mullon, P., Parada, C., Brochier, T., Penven, P. and Blanke, B. (2008). A Lagrangian tool for modelling ichthyoplankton dynamics. Environ. Model. Softw. 23, 1210-1214.

Lohmann, K. J. and Lohmann, C. M. F. (1994). Detection of magnetic inclination angle by sea turtles: a possible mechanism for determining latitude. J. Exp. Biol. 194, $23-32$.

Lohmann, K. J. and Lohmann, C. M. F. (1996). Detection of magnetic field intensity by sea turtles. Nature 380, 59-61.

Lohmann, K. J. and Lohmann, C. M. F. (2003). Orientation mechanisms in hatchling sea turtles. In Loggerhead Sea Turtles (ed. A. B. Bolten and B. E. Witherington), pp. 44-62. Washington, DC: Smithsonian Institution Press.

Lohmann, K. J., Cain, S. D., Dodge, S. A. and Lohmann, C. M. F. (2001). Regiona magnetic fields as navigational markers for sea turtles. Science 294, 364-366.

Lohmann, K. J., Lohmann, C. M. F. and Putman, N. F. (2007). Magnetic maps in animals: nature's GPS. J. Exp. Biol. 210, 3697-3705.

Lohmann, K. J., Putman, N. F. and Lohmann, C. M. F. (2012). The magnetic map of hatchling loggerhead sea turtles. Curr. Opin. Neurobiol. doi: 10.1016/j.conb.2011.11.005.

Luschi, P., Hays, G. C. and Papi, F. (2003). A review of long-distance movements by marine turtles, and the possible role of ocean currents. Oikos 103, 293-302.

McCleave, J. D., Brickley, P. J., O'Brien, K. M., Kistner-Morris, D. A., Wong, M. W., Gallagher, M. and Watson, S. M. (1998). Do leptocephali of the European eel swim to reach continental waters? Status of the question. J. Mar. Biol. Assoc. U.K. 78, 285 306.

Monzón-Argüello, C., Rico. C., Carreras, C., Calabuig, P., Marco, A. and LopezJuardo, L. F. (2009). Variation in spatial distribution of juvenile loggerehead turtles in the eastern Atlantic and western Mediterranean Sea. J. Exp. Mar. Biol. Ecol. 373, 7986.

O'Hara, J. (1980). Thermal influences on the swimming speed of loggerhead turtle hatchlings. Copeia 1980, 773-780.

Okuyama, J., Kitagawa, T., Zenimoto, K., Kimura, S., Arai, N., Sasai, Y. and Sasaki, H. (2011). Trans-Pacific dispersal of loggerhead turtle hatchlings inferred from numerical simulation modeling. Mar. Biol. 158, 2055-2063.

Paris, C. B., Cherubin, L. M. and Cowen, R. K. (2007). Surfing, spinning, or diving from reef to reef: effects on population connectivity. Mar. Ecol. Prog. Ser. 347, 285-300.

Putman, N. F., Shay, T. J. and Lohmann, K. J. (2010). Is the geographic distribution of nesting in the Kemp's ridley turtle shaped by the migratory needs of offspring? Integr. Comp. Biol. 50, 305-314.

Putman, N. F., Endres, C. S., Lohmann, C. M. F. and Lohmann, K. J. (2011). Longitude perception and bicoordinate magnetic maps in sea turtles. Curr. Biol. 21, 463-466.

Revelles, M., Carerras, C., Cardona, L., Marco, A., Bentivegna, F., Castillo, J. J., Martino, G., Mons, J. L., Smith, M. B., Rico, C., et al. (2007). Evidence for an asymmetrical size exchange of loggerhead sea turtles between the Mediterranean and the Atlantic thought the Straits of Gibraltar. J. Exp. Mar. Biol. Ecol. 349, 261-271.

Salmon, M. and Wyneken, J. (1987). Orientation and swimming behavior of hatchling loggerhead turtles Caretta caretta L. during their offshore migration. J. Exp. Mar. Biol. Ecol. 109, 137-153.

Scott, R., Marsh, R. and Hays, G. C. (2011). A little movement orientated to the geomagnetic field makes a big difference in strong flows. Mar. Biol. 159, 481-488.

Weishampel, J. F., Bagley, D. A. and Ehrhart, L. M. (2003). Earlier nesting by loggerhead sea turtles following sea surface warming. Glob. Change Biol. 10, 1424 1427.

Werner, F. E., Page, F. H., Lynch, D. R., Loder, J. W., Lough, R. G., Perry, R. I., Greenberg, D. A. and Sinclair, M. M. (1993). Influences of mean advection and simple behavior on the distribution of cod and haddock early life stages on Georges Bank. Fish. Oceanogr. 2, 43-64.

Whelan, C. I. and Wyneken, J. (2007). Estimating predation levels and site-specific survival of hatchling loggerhead sea turtles (Caretta caretta) from south Florida beaches. Copeia 2007, 745-754.

Wiltschko, W. and Wiltschko, R. (2005). Magnetic orientation and magnetoreception in birds and other animals. J. Comp. Physiol. A 191, 675-693.

Witherington, B. E. (2002). Ecology of neonate loggerhead turtles inhabiting lines of downwelling near a Gulf Stream front. Mar. Biol. 140, 843-853.

Witt, M. J., Hawkes, L. A., Godfrey, M. H., Godley, B. J. and Broderick, A. C. (2010) Predicting the impacts of climate change in globally distributed species: the case of the loggerhead turtle. J. Exp. Biol. 213, 901-911. 